\title{
ELECTRICAL RESISTIVITY OF LIQUID CuSn, CuSnBi, CuSnBiIn, CuSnBiInCd ALLOYS OF EQUIATOMIC COMPOSITIONS
}

\author{
Ilyin V.Yu. ${ }^{1 *}$, Chikova O.A. ${ }^{1,2}$, V'yukhin V.V. ${ }^{1}$, Abrosimov V.O. ${ }^{2}$ \\ ${ }^{1}$ Ural Federal University, Yekaterinburg, Russia \\ ${ }^{2}$ Ural State Pedagogical University, Yekaterinburg, Russia \\ *E-mail: gammaraylaser@yandex.ru
}

The resistivity of liquid CuSn, CuSnBi, CuSnBiIn, CuSnBiInCd alloys of equiatomic compositions are measured using the rotating magnetic field method to obtain information on their liquid structures. We see the alloys of equiatomic composition as the high-entropy alloys (HEAs). The change in the temperature coefficient of the resistivity of the melts on heating to $\mathrm{T}^{*}=800^{\circ} \mathrm{C}$ is interpreted using the Nagel-Tauc model.

The multicomponent alloys or compositionally complex alloys $\mathrm{CuSn}, \mathrm{CuSnBi}$, $\mathrm{CuSnBiIn,} \mathrm{CuSnBiInCd}$ of equiatomic compositions, it is the high-entropy alloys (HEAs), as structural materials, are drawing extensive attention from materials scientists [1]. At temperatures higher than the liquidus temperatures, multicomponent metallic high-entropy alloys can have microheterogeneities, whose chemical compositions are different from the compocomposition of the surrounding melt, for a long time [2]. To destroy these microheterogeneities, a liquid metal should be overheated to the temperature that is certain for each composition. After such an action, a melt transforms irreversibly into the state of true solution, which substantially changes the conditions of its solidification.

This work is devoted to investigations of the electrical resistivity of liquid $\mathrm{CuSn}$, $\mathrm{CuSnBi}, \mathrm{CuSnBiIn}, \mathrm{CuSnBiInCd}$ alloys of equiatomic compositions, as the most promising HEAs as solder. The resistivities were measured using the rotating magnetic field method during heating and subsequent cooling. A working chamber was initially evacuated to $0,001 \mathrm{~Pa}$, and, then, was filled with helium to a pressure of $10^{5} \mathrm{~Pa}$. The electrical resistivity was measured using the unit described in [3]. Its accidental component, which determined the accuracy of fixing anomalous points in the temperature dependences of $\rho$, was no higher than $2 \%$ at a confidence coefficient $p=0,95$. Figure 1 show results of a resistivity of the liquid alloys $\mathrm{CuSn}, \mathrm{CuSnBi}, \mathrm{CuSnBiIn}, \mathrm{CuSnBiInCd}$ study. The all liquid alloys demonstrate different temperature dependence of resistivity for heating and cooling. By heating the resistivity changes occurs nonmonotonically. All the investigated melts demonstrate the change in the temperature coefficient of the resistivity for heating at temperature $\mathrm{T}^{*}=800^{\circ} \mathrm{C}$. It was determining the temperature $\mathrm{T}^{*}$ is the temperature of the changes the microheterogeneous structure of a metallic melt. The temperature coefficient of the resistivity was positive in experiments with heating. For cooling alloys $\mathrm{CuSnBi}, \mathrm{CuSnBiIn}, \mathrm{CuSnBiInCd}$, the temperature coefficient of resistivity was negative or had the magnitude close to zero. A similar result was obtained earlier on measuring the electrical resistivity of steel. The change in the temperature 
coefficient of the resistivity of the melts on heating to $\mathrm{T}=1500 \mathrm{~K}$ is interpreted using the Nagel-Tauc model [3].

CuSn

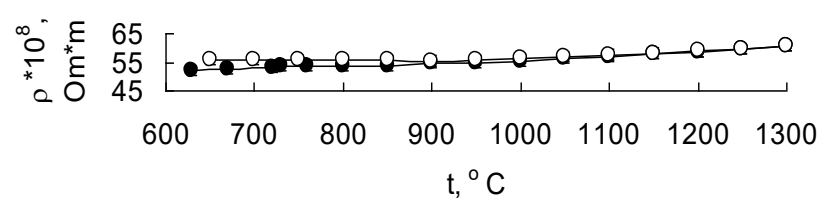

CuSnBi

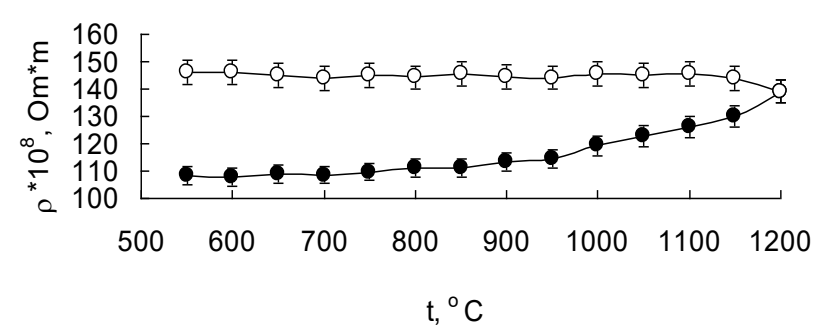

CuSnBiln

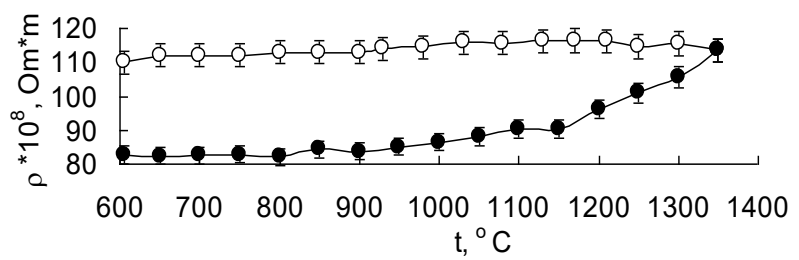

CuSnBilnCd

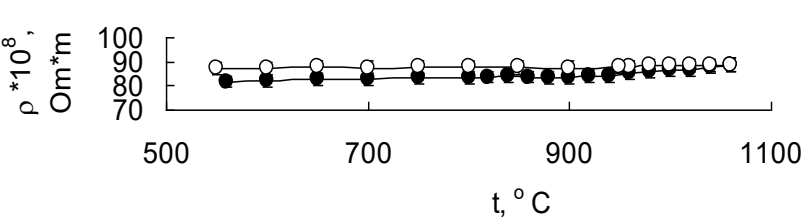

Fig. 1. The temperature dependences of the resistivity of the CuSn, CuSnBi, CuSnBiIn, $\mathrm{CuSnBiInCd}$ equiatomic composition melts $(\bullet-$ heating, $\bigcirc-$ cooling $)$

1. Miracle D.B., Senkov O.N., Acta Materialia, 122, 448-511 (2017).

2. Chikova O.A., Il'in V.Y., Tsepelev V.S., V'yukhin V.V., Inorganic Materials, 52, 517522 (2016).

3. Borovykh M.A., Chikova O.A., Tsepelev V.S., V'yukhin V.V., Russian Metallurgy (Metally), 3, 175-178 (2017). 